\title{
Designing to Inform: Toward Conceptualizing Practitioner Audiences for Socio-technical Artifacts in Design Science Research in the Information Systems Discipline
}

\author{
Andreas Drechsler \\ University of Duisburg-Essen, Essen, Germany \\ University of South Florida, Tampa, FL, USA \\ andreas.drechsler@icb.uni-due.de
}

\begin{abstract}
This paper identifies areas in the design science research (DSR) subfield of the information systems (IS) discipline where a more detailed consideration of practitioner audiences could improve IS DSR's informing power and proposes an initial audience conceptualization in an informing system. The consequences of not considering artifact audiences in greater detail are identified through a critical appraisal of the current informing science lenses in the IS DSR literature. The paper identifies four yet underdeveloped areas in the discourse: 1) treating practice stakeholders as a too homogeneous group, 2) not explicitly distinguishing between social and technical parts of socio-technical artifacts, 3) neglecting implications of the artifact abstraction level, and 4) a lack of explicit consideration of a dynamic or evolutionary fitness perspective of socio-technical artifacts. The findings pave the way for future research to further improve the conceptualization of artifact audiences, in order to improve the informing power - and thus, impact on practice and research relevance - of IS DSR projects. The findings can also serve as a first step to bridge the theory-practice gap in and, thus, improve the informing power of other disciplines (e.g., computer science, engineering, or policy-oriented sociology) that seek to produce social and/or technical human-created artifacts of practical relevance.
\end{abstract}

Keywords: design science, informing science, artifacts, artifact audiences, relevance, fitness, utility

\section{Introduction}

Material published as part of this publication, either on-line or in print, is copyrighted by the Informing Science Institute.

Permission to make digital or paper copy of part or all of these works for personal or classroom use is granted without fee provided that the copies are not made or distributed for profit or commercial advantage AND that copies 1) bear this notice in full and 2) give the full citation on the first page. It is permissible to abstract these works so long as credit is given. To copy in all other cases or to republish or to post on a server or to redistribute to lists requires specific permission and payment of a fee. Contact Publisher@InformingScience.org to request redistribution permission.
One characteristic of the information systems (IS) discipline in its current state is the co-existence of two major research paradigms. The first and most traditional paradigm is explanationoriented and theory-building empirical research to understand real-world phenomena in the context of IS development or use (Gregor, 2006). The other paradigm - design science research (DSR) - seeks to design and evaluate 
socio-technical IT artifacts that provide potential solutions for classes of real-world problems and ground them in existing theory (Gregor \& Hevner, 2013).

Since many disciplines use the term "artifact", I will define it first in the sense the IS discipline commonly understands the term. This understanding goes back to Simon (1996) who (first in 1969) distinguished the natural sciences and the sciences of the artificial. The latter are concerned with human-made entities, the so-called artifacts. In the IS discipline, socio-technical artifacts are at the center of interest (Gregor \& Hevner, 2013). They comprise an ensemble of technical elements (such as concepts, models, methods, or instantiations (March \& Smith, 1995) of information technology) and/or social elements (humans, roles, work processes, teams, groups, etc.) of organizations.

A typical DSR research process to design a socio-technical artifact starts with identifying a realworld problem and defining objectives for the solution development (Peffers, Tuunanen, Rothenberger, \& Chatterjee, 2007). Afterwards, the actual design and development phase starts, which gives the name to DSR. The designed artifact is then to be applied to the problem context in order to demonstrate suitability to solve the problem that triggered the DSR process. When an artifact is indeed able to fulfill the objectives, it is said to have utility. The next phase, the artifact evaluation, seeks to assess an artifact's impacts and utility in greater detail, its superiority to other solutions (if applicable), and to derive future artifact improvements based on experiences during its application. In the final phase, the researchers communicate the artifact and the corresponding lessons learned throughout the process of design, application, and evaluation to researchers as well as to professionals in practice. In other words, this final phase is the one where the DSR literature in its current state is concerned with informing stakeholders.

Over the past decade, IS DSR has seen a tremendous development of theoretical and methodical foundations (Gill \& Hevner, 2013; Gregor \& Jones, 2007; Hevner \& Chatterjee, 2010; Hevner, March, Park, \& Ram, 2004; Kuechler \& Vaishnavi, 2012; Peffers et al., 2007; Vaishnavi \& Kuechler, 2008), as well as high-quality publications of actual DSR research projects (Arazy, Kumar, \& Shapira, 2010; Reinecke \& Bernstein, 2013; VanderMeer, Dutta, \& Datta, 2012). Arazy et al. (2010) design and evaluate an algorithm for a social recommender system, based on behavioral theory. Reinecke and Bernstein (2013) design and evaluate a model, a method, and a sample instance to adapt user interfaces of software applications based on the users' culture. VanderMeer et al. (2012) design and evaluate an algorithm to improve the resource utilization for database systems with a high percentage of read-intensive database operations.

These three artifacts illustrate the broad range of artifact types and domain foci of today's IS discipline. Initially, the discipline's main research focus lay on IT artifacts in - typically business organizations (Orlikowski \& Iacono, 2001). Nowadays, its application domains extend to, among others, healthcare IT (Chiasson, Reddy, Kaplan, \& Davidson, 2007), social media (Krasnova, Spiekermann, Koroleva, \& Hildebrand, 2010), or sustainability (Pernici et al., 2012). Likewise, its subject matters extend more and more beyond a technology focus to socio-technical information systems in organizations that comprise information, technology, people, organizational structures and processes, and their relationships (Nunamaker, Jr. \& Briggs, 2012).

While the three high-quality DSR publications mentioned above allow one to infer that DSR as a research paradigm has gained acceptance within the IS discipline, neither publication reports actual artifact adoption in practice. This is of particular importance, since proponents of DSR have historically developed this paradigm at least partially as a reaction to calls to increase IS research's practical relevance (Benbasat \& Zmud, 1999; Davenport \& Markus, 1999; Iivari, 2003; Kock et al., 2002; Kuechler \& Vaishnavi, 2008; Nunamaker, Jr. \& Briggs, 2012). The overall intention behind many of the publications cited above is to inspire other IS researchers to set their future research agendas accordingly and in a conscious way. A common denominator in 
the IS relevance debate is the call to researchers to make their research more relevant to practice, to inform their clients in practice better about relevant research outcomes, therefore to increase the impact of IS research to practice, and, in the end, help the IS discipline to grow stronger over time. In the current DSR discourse, the relevance of research outcomes is commonly operationalized as artifact utility - the dependent variable (Gill \& Hevner, 2013).

There have been some attempts in the literature to address the relevance problem of IS and DSR relevance by applying an informing science lens (Gill \& Bhattacherjee, 2009; Kuechler \& Vaishnavi, 2011). Informing science is an academic transdiscipline and concerns the study of informing processes (Cohen, 1999, 2009). Informing processes take place between one or more classes or types of clients and professionals, such as researchers (Birdsall, 2009). Informing science's goal is to inform a clientele "in a form, format, and schedule that maximizes [...] effectiveness" (Cohen, 2009, p. 6). Informing science combines insights from diverse academic disciplines such as philosophy, psychology, communication, library science, education, management, information systems, and computer science.

In an informing science perspective, design research differs fundamentally from traditional empirical explanation-oriented research in that it does not focus on explaining real-world phenomena to an audience. Instead, it focuses on designing artifacts that provide solutions for classes of realworld problems and are therefore useful. However, in the DSR literature, artifact utility is commonly treated "as such," with no specific agency, contextualization, or audience. This leads to the conclusion that current DSR discourse has neglected its design artifacts' audiences. With a single exception (Gill \& Hevner, 2013), there is also no dynamic perspective - to remain useful even in changing circumstances and contexts - on artifact utility. Gill and Hevner (2013) operationalize this dynamic perspective on artifacts as artifact fitness. However, they mainly focus on technical artifacts. For artifacts with a stronger social component - such as IS/IT management frameworks or instruments - initial research indicates that artifact fitness becomes an even more complex matter when considering different stakeholders from practice (Drechsler, 2014).

Taken together, current DSR approaches for artifact design and communication - and hence, informing - may not deliver artifacts that can fulfill their potential sustained utility for their user audiences to the fullest. In turn, the unfulfilled potential of current DSR approaches limits their actual relevance to specific target audiences in practice. In this light, this paper identifies specific areas where the current conceptual and methodological foundations of IS DSR are lacking concerning artifact audiences in the realm of practice. To do so, this paper first briefly describes the existing informing sciences perspectives on IS DSR. It then identifies four areas with room for improvement through criticizing and discussing existing informing science perspectives. Based on such criticism, in this paper I propose an initial conceptualization of artifact audiences to extend existing informing science perspectives. Finally, the paper outlines the next steps to derive concrete implications for DSR methodologies and guidelines for design science researchers to consider artifact audiences during design time in the future.

Since the eventual findings are only partially specific to the IS discipline's socio-technical nature, they may also be applicable to other disciplines that seek to produce social and/or technical artifacts of relevance for audiences in practice. Therefore, the findings can form starting points to further increase these disciplines' relevance and their informing power for practice. This includes disciplines such as computer science and software engineering, which seek to produce practically relevant technical artifacts (Kuechler \& Vaishnavi, 2011), but also parts of the management or sociology disciplines that seek to develop prescriptive theory-based and evidence-based action strategies for managers (Rosseau, 2012) or social policies to alleviate social issues (Pawson, 2006) - in other words, social artifacts. 


\section{Existing Informing Science Perspectives on IS DSR}

Gill and Bhattacherjee (2009) discuss the key implications of an informing science perspective for the IS discipline as a whole. They identify three classes of clients for IS research: other researchers, students, and MIS practitioners. The latter include IT experts, IT executives, and IT consultants. They further identify several communication barriers (e.g., the different knowledge types that researchers and practitioners value) and dissemination barriers (including the lack of close ties with innovation leaders) that currently prevent the IS discipline from informing its practitioner clientele with maximum effectiveness, thus constituting obstacles to IS research relevance. In the end, they explicitly name DSR as one research method that IS researchers can employ to increase their interaction with practitioner clients. However, Gill and Bhattacherjee do not provide a more fine-grained perspective on MIS practitioners, nor do they go into specific detail as to how DSR can specifically overcome the communication barriers for the different MIS practitioner types they identified.

Kuechler and Vaishnavi (2011) take a DSR-specific stance when applying an informing science perspective to IS research. Similar to Gill and Bhattacherjee (2009), they take a comprehensive perspective on the corresponding informing system, for instance including tenure promotion committees or research grant institutions as specific subclasses for the stakeholder class other IS researchers. They outline common issues in research-practice collaboration that prevent easy accomplishment of both researchers' and practitioners' goals. They further highlight the science aspect of design science research through learning and building knowledge by means of rigorous design. However, they do not take a more in-depth look at different IS practitioner stakeholder subclasses, nor do they provide recommendations for the actual IS DSR artifact design process that include stakeholder-specific or audience-specific factors.

Hevner et al. (2014) provide a bridge between current neuroscientific theory and IS DSR to illustrate, in an informing science perspective, how to include stakeholders and achieve consensus during the design process. However, they emphasize design task characteristics such as unfamiliarity, complicatedness, and complexity or design activities such as designer creativity and do not delve further into different DSR process stakeholder types.

Finally, Gill and Hevner (2013) propose considering artifact fitness in addition to utility as sole dependent variable. They do not take an explicit informing science perspective, but implicitly consider the design artifacts' informing power over time. For instance, their fitness concept includes criteria such as interest (for an audience, so that the artifacts are adopted) or malleability (so that the artifacts can be adapted to their audiences' application contexts and remain useful). However, they do not more specifically look into different stakeholder or audience classes, nor how these influence different fitness criteria's roles or importances. In addition, they focus on artifacts with a heavy emphasis on the technological component (e.g., open source software, Linux vs. UNIX, or the SABRE airline booking system).

\section{Limitations of the Current Discourse}

A critical analysis of the current informing science and IS DSR literature landscape reveals four areas with relevance for informing practitioner audiences which have not received much research attention yet. This section discusses these four areas and how their consideration can improve the discipline's informing power. Furthermore, the discussion provides the elements for the initial conceptualization of artifact audiences of practice.

\section{Consideration of Specific Practitioner Stakeholder Subgroups}

All existing informing science perspectives have in common that they do not differentiate further between the fairly generic practitioner stakeholder subgroups of IT experts, IT executives, and IT 
consultants (Gill \& Bhattacherjee, 2009) or IS or IT practitioners (Kuechler \& Vaishnavi, 2011). While the differentiations make sense in the scope of the respective papers, they provide little specific guidance when designing artifacts to inform specific practitioner audiences. The three subgroups are also not without overlaps - IT executives and consultants may or may not be IT experts at the same time. The remaining DSR literature also does not explicitly cover different stakeholder groups or audiences, but often assumes a uniform artifact utility as dependent variable (Gill \& Hevner, 2013).

The relevant artifact audience will most likely depend on the designed artifact type. Considering the artifact type is a specific challenge in the IS discipline, because a wide range of different types of socio-technical artifacts fall inside its scope. For analytical purposes, Drechsler and Dörr (2014) propose differentiating between four types of socio-technical artifacts within IS (see Table 1). Although very brief, Drechsler and Dörr's analysis indicates that explicit consideration of different artifact audience types for each artifact type can help convey an artifact's potential utility and actual utility, while disregarding them may weaken them.

\begin{tabular}{|c|c|c|c|}
\hline Туре & Description & Example & Audiences \\
\hline $\begin{array}{l}\text { Technical arti- } \\
\text { facts }\end{array}$ & $\begin{array}{l}\text { Hardware and software } \\
\text { systems (or parts thereof), } \\
\text { no end-user interaction }\end{array}$ & $\begin{array}{l}\text { An algorithm for handling large } \\
\text { amounts of data in distributed } \\
\text { database management systems }\end{array}$ & $\begin{array}{ll}- & \text { IT executives } \\
- & \text { IT experts } \\
- & \text { IT consultants }\end{array}$ \\
\hline $\begin{array}{l}\text { Technical arti- } \\
\text { facts that con- } \\
\text { sider social as- } \\
\text { pects }\end{array}$ & $\begin{array}{l}\text { Technical artifacts that } \\
\text { include the end-users' } \\
\text { perspective. }\end{array}$ & $\begin{array}{l}\text { A software system for use with- } \\
\text { in business processes such as } \\
\text { enterprise resource planning } \\
\text { software }\end{array}$ & $\begin{array}{ll}- & \text { Business execu- } \\
\text { tives } \\
- & \text { IT executives } \\
- & \text { Business experts } \\
- & \text { IT experts } \\
- & \text { Consultants } \\
- & \text { Artifact end- } \\
& \text { users }\end{array}$ \\
\hline $\begin{array}{l}\text { Socio-technical } \\
\text { artifacts }\end{array}$ & $\begin{array}{l}\text { Artifacts that comprise IT, } \\
\text { people, and processes } \\
\text { comprehensively and } \\
\text { integratively. }\end{array}$ & 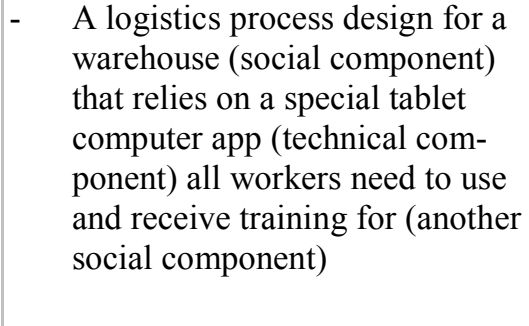 & $\begin{array}{ll}- & \text { Business execu- } \\
\text { tives } \\
- & \text { IT executives } \\
- & \text { Business experts } \\
- & \text { IT experts } \\
- & \text { Consultants } \\
- & \text { Artifact end- } \\
& \text { users }\end{array}$ \\
\hline Social artifacts & $\begin{array}{l}\text { Artifacts that comprise } \\
\text { social / organizational } \\
\text { structures, processes, and } \\
\text { people }\end{array}$ & $\begin{array}{l}\text { - A framework for distributed } \\
\text { agile software project manage- } \\
\text { ment }\end{array}$ & $\begin{array}{ll}\text { - } & \text { Domain execu- } \\
\text { tives } \\
\text { - } & \text { Domain experts } \\
\text { - } & \text { Consultants } \\
\text { - } & \text { Artifact end- } \\
& \text { users }\end{array}$ \\
\hline
\end{tabular}

Purely technical artifacts imply that there is no direct interaction between them and end-users and they therefore form part of hardware or software products or solutions. In terms of audiences, this means that IT experts are addressed first and foremost, but without IT executives deciding on integration of a particular technology or algorithm into a product or solution, the artifact is not effectively put to use, and its utility is not realized. While the former audience may be convinced 
by technical superiority (and hence, utility) alone, for the latter the decision to adopt the artifact usually rests on a sound business case. A third audience type that may play a role in the artifact adoption and use process of technical artifacts is IT consultants as technical consultants with a strong technical expertise. Hence, IT experts, IT executives, and IT consultants are the first three audiences for an informing system for technical IT artifacts.

However, taking the typical example of an end-user enterprise software system for a technical artifact that considers the social factor, we get at least four different audiences: IT executives (who evaluate the artifact's technical feasibility), business executives (who evaluate the artifact's business-related feasibility), artifact end-users (who use the artifact's actual utility for their individual tasks), and the enterprise as a whole (to actually realize business value from using the artifact as part of the end-to-end business processes). Here, IT consultants as a fifth audience may also play a role in bringing an artifact to the executives' attention or to support the introduction process. The consultants may also have a more technical and/or a more business-oriented focus. Furthermore, the aforementioned executives may employ internal business or technical experts to help assess an artifact. Compared to a purely technical artifact, a more technically oriented audience is complemented with audiences with business expertise here. Both audiences perceive different artifact properties and hence evaluate different facets of an artifact's utility. Both utility types are complementary, and limitations in one area may limit an artifact's overall utility. Consequently, the number of audiences in the informing system rises from three to six and now includes business executives, business experts, and end-users as well.

The argumentation for the third artifact type - the comprehensively socio-technical artifact follows similar lines, but with different emphasis. While formerly the technical artifact was at the center of the attention and its social application was part of the context, both realms are weighted more equally for a comprehensively socio-technical artifact. Here, technical considerations may well come second - both in terms of designers' interests or intentions as well as audiences' perceptions - to social or business aspects. A further shift of emphasis towards the organizational or social audience takes place when considering a predominantly social artifact as the fourth and final artifact type.

In sum, even with the limitations of a still rather abstract distinction of four artifact types and a traditional business organization focus of IS research, we can achieve a more differentiated perspective on artifact audiences than what currently exists in the IS DSR discourse. The different audience types mean that there is no unified concept of artifact utility among them. In turn, this leads to the need for design science researchers to consider informing the different audience types about different artifact properties and potentials in distinct ways.

\section{The Consideration of Different Types of Research Relevance and Artifact Utility for Different Stakeholder Groups}

To take a closer look at different concepts of artifact utility - and thus artifact relevance - for different audiences, it makes sense to also take a more differentiated perspective on research relevance. While the sources cited in this section do not take an explicit informing science perspective, they effectively regard research relevance as the informing power of research outcomes for practitioner audiences. Therefore I regard their perspectives as informing science perspectives at least in spirit.

Nicolai and Seidl (2010) distinguish three types of relevance of management research outcomes: conceptual, instrumental, and legitimative relevance. They base this distinction on a classification of research outcomes in top management journals. In their classification scheme, research is conceptually relevant when it has the potential to guide and inspire managerial decisions and actions. They name the identification of causal relationships through empirical research as a typical ex- 
ample for conceptually relevant research. In contrast, research is of instrumental relevance when the outcomes are intended to be immediately useful and applicable in managerial practice. Nicolai and Seidl (2010) provide the examples of decision support schemes (matrixes, flow charts, etc.), forecasts, and technological rules. The third research relevance type - legitimative relevance occurs when research outcomes are solely used to justify managerial action. While Nicolai and Seidl exclusively focus on management research, their distinction is nonetheless also useful for analyzing DSR research outcomes. Since legitimative relevance is an undesirable form of relevance, it is left outside the scope of the remainder of this paper.

Applying the remaining distinction between conceptual and instrumental relevance to the current understanding of artifact utility in IS DSR discourse points to an instrumental understanding of artifact relevance, since the literature regards artifact utility as key indicator of relevance to inform the IS research clients. However, Nicolai and Seidl (2010) are very critical of research outcomes of instrumental relevance. To them, necessarily abstract research outcomes cannot take into account the specifics of future application contexts. Taken together with the different audiences identified in the previous section, a more fine-grained picture emerges.

The first step to achieving practical utility for an existing DSR artifact is a practitioner's perception of the artifact's potential utility. In other words, practitioners first need to be informed about an artifact (for instance, by its designers), become aware of its existence, perceive it, and assess whether they can see how its adoption can benefit them or their organization, before actual artifact adoption can take place.

For a technical artifact, this can be the technical superiority an IT expert perceives or the potential for a positive business case an IT executive responsible for product decision-making perceives. In contrast, for an artifact with a social or organizational component, business executives need to perceive its general potential for additional business value (e.g., through increased process efficiency, more effective process designs, or entirely new business models) first. After the artifact passes through this barrier, the same or other executives or experts evaluate its actual feasibility, this time on a business as well as a technical level. In both cases, IT consultants can serve to inform executives or experts about an artifact's existence or can help evaluate its potential.

Relating this to the different relevance types leads to the conclusion that an artifact first needs to be of conceptual relevance for the aforementioned audiences. The artifact can only realize its actual utility - i.e., can become instrumentally relevant - only after the respective audiences decide in favor of its adoption for a specific context, based on its perceived conceptual relevance. The actual utility then is realized by its end-users - if the initial assessments of its potential were correct and it fulfills the end-users' needs. In this perspective, the formerly homogeneous construct utility can at least be split into potential utility (conceptual relevance) for decision-oriented audiences and actual utility (instrumental relevance) for audiences having to deal with an artifact in their daily work.

This likewise applies to technical parts of artifacts (e.g., a software system that is fit for a purpose and also user-friendly) as well as their social/organizational parts (e.g., an overall effective process framework that is then split into manageable roles and tasks for the persons executing the process).

One further important aspect that influences the ease with which practitioner audiences can be informed about an artifact's potential utility and evaluate it is its level of abstraction, as discussed in the upcoming section. 


\section{The Implications of an Artifact's Abstraction Level for its Informing Power}

The current DSR discourse distinguishes two different design artifact abstraction levels (Gregor \& Hevner, 2013): abstract artifacts, which provide (potential) utility for a class of contexts and problems, and instance-level (local) artifacts, which provide actual utility in a specific context and solve a specific problem. For researchers, this leads to two ways of approaching a DSR project: either to design a local-level artifact for a specific context - for instance, through a combination of action and design research (Sein, Henfridsson, Purao, Rossi, \& Lindgren, 2011) - and then think about its generalizability beyond the singular local context or to design an abstract artifact for a well-defined class of contexts and provide guidance on how to instantiate and customize the abstract artifact to specific contexts (Gregor \& Jones, 2007; van Aken, 2004).

The immediate advantages of the first approach lie in utility criteria for conceptual and instrumental relevance for the application context that are or can be made clear before the actual artifact design process starts. In such a case, the decision-oriented audiences are informed - and probably persuaded - by the researchers to allow the design research setting in the first place and do not have to be persuaded by the artifact's informing power alone. However, only the extent of actual generalizability of the eventual artifact at the end of the design effort determines whether there will be a generalized - and thus, abstract - artifact at all that applies to other contexts (Sein et al., 2011). In the worst case, the specifics of the particular context are unique and the artifact generalizability remains very limited. However, striving for abstraction is an integral part of the science component in design science research; this is emphasized by Kuechler and Vaishnavi (2011), among others. The extent of generalizability also affects the extent of the artifact's practical impact and, thus, relevance for other clients. If an artifact remains on the local level, its relevance contribution to the discipline is more limited than for an artifact of a grander scope.

For designing abstract artifacts, researchers' informing challenges are more numerous. The artifact initially needs to be designed to be potentially useful for a class of contexts. The researchers need to inform and convince decision-oriented practitioner audiences to further assess and eventually adopt it by convincingly demonstrating its potential utility (its conceptual relevance). During the artifact's evaluation, researchers will also face the challenge of attributing artifact utility (its instrumental relevance) to the abstract artifact or to the specifics of its local instance. Furthermore, for a truly broad practical impact (and thus, high overall relevance), the artifact's informing power should be independent from its designers, so that practitioners adopt it without researchers' personal interventions. This may, among others, require several positively evaluated artifact instantiation cases with a high visibility, which contribute to the respective artifact's conceptual relevance. Here, consultants can also play a key role in addressing this research-practice gap by informing new potential audiences (Carlsson, Henningsson, Hrastinski, \& Keller, 2010).

It is noteworthy that Gregor and Hevner (2013), in fact, further distinguish between abstract artifacts with a mid-range scope and those with a grand scope. The mid-range ones correspond to the abstract artifacts discussed in the previous paragraphs, while the artifacts with a grand scope are of an even higher level of abstraction. The latter may provide an increased satisfaction of the research goal of abstraction, but are even more difficult to instantiate for specific contexts than mid-range artifacts. Hence, they may possess only a limited informing power for practitioner audiences. Thus, they are intended for the researcher audience rather than any practitioner audience and therefore outside the scope of this paper. The same applies to the construct of design theories which some IS DSR researchers use as a substitute for artifacts as DSR outcomes (Gregor \& Hevner, 2013) and which encompass the artifacts themselves as well as additional constructs such as meta-requirements and testable propositions (Gregor \& Jones 2007). 
The implications of an artifact's abstraction level for its informing power discussed in this section apply in the same manner to more technical or more socially oriented socio-technical artifacts. However, an artifact's technical and social components differ in the extent and the easiness of their adaptability to different contexts. The next section covers this issue as part of artifact fitness.

\section{The Implications of a Dynamic/Evolutionary Artifact Fitness Perspective of Different Artifact Types}

Gill and Hevner (2013) propose to consider artifacts' fitness aspects in addition to their utility. They understand fitness in an evolutionary sense in two ways: first, that an abstract artifact can be adapted to (= be useful in) different contexts (reproduction) and, second, that an artifact on the instance level can provide sustained utility by adapting to changing contexts (survival). They operationalize fitness in the form of seven properties: decomposability, malleability, openness, novelty, interestingness, elegance, and being embedded in a design system.

Drechsler (2014) relates these properties to different artifact adoption phases and, to a certain extent, audiences. For the decision phase (and thus for informing a decision-making audience) before the artifact adoption (reproduction), he emphasizes fitness properties such as novelty, openness, elegance, interestingness (for decision-makers), or being embedded in a design system (the artifact being offered by consultants, for instance). To achieve sustained utility (survival), he considers fitness properties such as malleability, decomposability, openness, elegance (in terms of maintenance), or being embedded in a design (= change) system as being very important. However, in his analysis, he focuses on social artifacts with a managerial audience, while Gill and Hevner (2013) emphasize technical artifacts in their paper, limiting its generalizability.

This difference between more technical and more social artifacts is important owing to the fundamentally different nature of technical and social components of socio-technical artifacts. Social components such as process frameworks - as long as they are not yet implemented - are fairly easily malleable, decomposable, and open, since any audience can easily see them, change them, split them into parts, and connect them to other process models simply by making changes to the respective drawings and descriptions. In contrast, to change 'virtual' technical components in the form of software, specific persons with technical knowledge and access to the source code need to be employed to conduct the normal software engineering process in the form of requirements engineering, technical design, implementation, and testing. Changes to 'physical' technical components (such as hardware changes for embedded systems) require an even more time-consuming process of redesign, reengineering, and manufacturing. The extent of technical changes in both cases is also limited by the technical possibilities as well as the required effort. In comparison, changing process models or descriptions takes little effort.

This leads to significant implications for the transition between abstract socio-technical artifacts and instantiated (adapted and customized) local artifacts that need to attain and sustain actual utility over time. Specifically, the transition or instantiation phase requires less effort for a sociotechnical artifact's social components than for its technical components. Thus, an abstract artifact's potential utility (conceptual relevance for decision-oriented audiences) may be easier to achieve and demonstrate for its social than for its technical components.

To achieve sustained utility (instrumental relevance for the end-users and the overall organization), however, it may actually be other way around. It may well be the case that successful organizational change management of an established social system turns out to be the greater challenge than changing a piece of technology according to a defined process. Interestingly, this reversal does not necessarily apply to the extent of the general post-adoption artifact malleability owing to the nature of technical limitations (as discussed above). 
To further complicate the matter - unless the artifact in question is purely social or purely technical - only when taken together do the technical and social components form a socio-technical artifact, and both parts rely on close interdependencies and interactions, so that the overall artifact can achieve its intended purpose (and utility). This means that design researchers as well as the different audiences have to deal with different change speeds of the social and technical components of socio-technical artifacts in different phases of artifact pre-adoption and post-adoption. In turn, all these factors influence the types and extent of artifact fitness, relevance, and utility in the different phases - and, thus, also an artifact's informing power.

\section{The Initial Conceptualization of Practitioner Audiences for IS DSR Artifacts}

Based on the discussion in the previous section, I propose the initial conceptualization of practitioner audiences for IS DSR artifacts in an informing system (as shown in Figure 1).

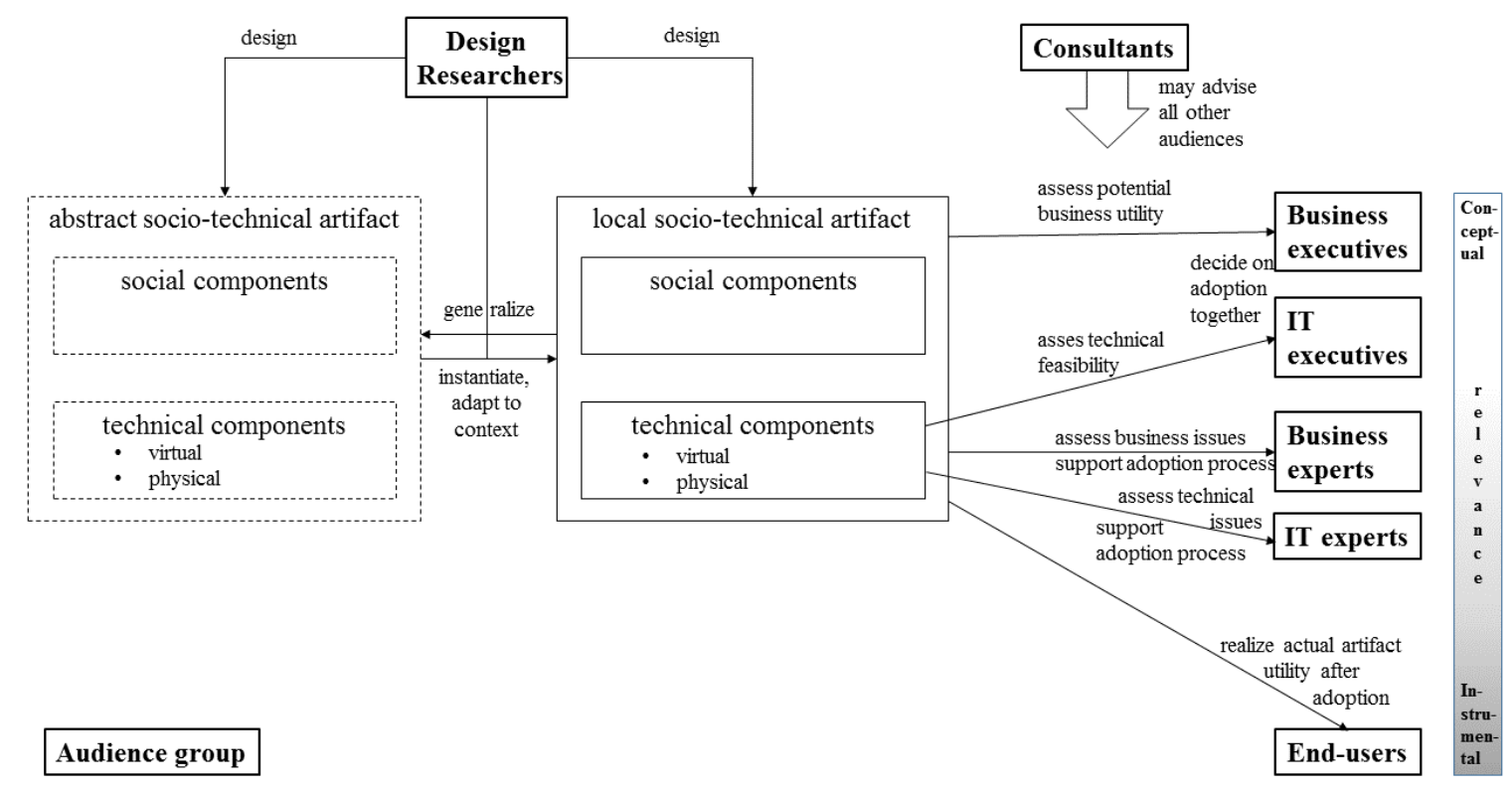

Figure 1: Initial Conceptualization of Practitioner Audiences and Socio-technical DSR Artifacts in an Informing System

Figure 1 summarizes the distinctions between abstract and instantiated (local) artifacts, the different component types of socio-technical artifacts, the different audiences and their individual roles and perspectives/perceptions of the artifact, and the different types of artifact relevance for the different audiences. The figure illustrates that conceptual relevance (or potential artifact utility) initially plays a greater role for an artifact's informing power than instrumental relevance (or actual artifact utility) during the decision process before the artifact is actually adopted and can deliver its actual utility within an organizational setting. The non-decision-making experts have a hybrid role here. To them, the artifact's conceptual relevance is of higher importance during the decision phase where they supply the executives with their assessments, while the instrumental relevance becomes more important when they support the artifact's actual adoption process.

It is noteworthy that the business audiences will tend to perceive the socio-technical artifact as a whole (the social components such as process descriptions and at least the technical artifact's user 
interface components), while the technical audiences may tend to primarily perceive its technical components. In case of a purely social artifact, the technical audiences do not play a role in the corresponding informing system, while in case of a purely technical artifact at least some audiences with a business orientation can still play a role in decision-making.

Furthermore, the audiences represent roles rather than individual persons, so it is conceivable that the design researchers can act as consultants towards the audiences within the artifact's application context, for instance. The same person can also take the role of business and IT executive if he or she is the sole decision-maker for a socio-technical artifact's adoption. Not depicted in Figure 1 is the dynamic perspective of artifact fitness in terms of sustaining utility over time despite different change speeds of social and technical artifact components.

\section{Discussion and Limitations}

This paper identified and discussed yet underdeveloped areas in current IS DSR discourse concerning informing practitioner audiences of artifacts and proposed a first conceptualization of different artifact audience groups of practice. Considering them - along with the other aspects discussed - during artifact design time has the potential to increase artifacts' practical impacts and can, in turn, further increase the IS discipline's research relevance and informing power for its clients. The conceptualization of Figure 1 is complementary to existing papers with an informing science lens on the IS discipline and the DSR research paradigm (Gill \& Bhattacherjee, 2009; Kuechler \& Vaishnavi, 2011). While the latter two papers take a more comprehensive perspective on the respective informing systems, this paper looks into greater detail into the informing subsystem that, in the end, determines the perceived practical relevance of the IS discipline and constitutes the arena in which DSR artifacts' actual utility is realized.

The conceptualization is a first step for researchers to take informed decisions at the start of a DSR project about what type of artifact (abstract or local) they want to design. They can further derive artifact properties not only in a theory-driven way, but also by taking into account the different types of relevance and the informing needs of the different audiences. The conceptualization also fosters the separate - and the same time, integrated - consideration of social and technical components and different audience groups. It further encourages researchers to consider complementary communication and informing strategies for artifacts before, during, and after the research publication efforts.

However, this conceptualization is not without limitations. Figure 1 shows an initial proposal of a purely conceptual nature, based on a discussion of the current literature. It has not yet been evaluated or related to existing DSR papers. Further, it takes a "classic" stance on a business context for IS research, with typical examples for each of the four artifact types. It does not account for the broad range of artifacts in modern IS research, for instance, from the domains of healthcare IT (Kenneally, Curley, Wilson, \& Porter, 2013) or smart cities (Maccani, Donnellan, \& Helfert, 2014). For each of these domains, different audiences with different informing requirements as well as different forms and manifestations of social and technical components of the respective socio-technical artifacts may become relevant. Furthermore, the specific informing challenges for each arrow in Figure 1 were not analyzed. Here, Kuechler and Vaishnavi's (2011) paper can serve as a starting point, since they already discuss several general communication challenges of researchers with the business domain. Again, other domains may also face other specific communication challenges. 


\section{Conclusion}

This paper identified yet under-researched areas in the literature concerning the treatment of practitioner audiences for design science research outcomes (artifacts) in the IS discipline and presented an initial conceptualization of artifact audiences in an informing system. I hypothesized that considering these audiences more deliberately and in greater detail during an artifact's design will increase an artifact's actual utility, relevance, and informing power and, in the long term, the practical relevance of the discipline as a whole. The initial conceptualization is intended to form the foundation for further research steps.

\section{Outlook}

The next planned step is to analyze how recent IS DSR papers addressed informing their practitioner audiences and how many different application contexts they cover. The papers are to be identified by means of a structured literature review (Webster \& Watson, 2002) of the top IS journals (as listed in the "Senior Scholar's Basket of Eight" of the Association of Information Systems) as well as the proceedings of the premier design science conference DESRIST from the past ten years. This timeframe covers all years after a hallmark paper (Hevner et al., 2004) on IS DSR appeared that triggered increased interest in IS DSR in the international research community. (Note that some national IS research communities such as the German and Scandinavian ones have been conducting DSR for a longer period of time, but with partially differing conceptual and methodological underpinnings, limiting comparability to current papers.) An analysis along similar lines in related disciplines (e.g., computer science, software engineering, evidence-based management, and policy-oriented sociology) can reveal how they inform their practitioner audiences and whether the IS discipline is unique in its complex audience landscape.

After that, the goal is to revise the initial concept of artifact audiences based on the insights gained from the analyses and discuss it again with the informing science and information systems communities. In the end, the intention is to develop a set of guidelines for IS DSR researchers to consider informing their artifact audience landscape during the design, application, evaluation, and publication phases of their DSR projects in order to maximize impact and relevance. These guidelines then need to prove their validity in actual DSR projects - whether considering an artifact's audiences during design time in a differentiated way helped attain its practice relevance. In this way, this initial conceptualization constitutes the first step to further realize the promising potential of IS DSR to increase the discipline's practical relevance through informing the 'right' stakeholders in the 'right' way.

\section{References}

Arazy, O., Kumar, N., \& Shapira, B. (2010). A theory-driven design framework for social recommender systems. Journal of the Association for Information Systems, 11(9), 455-490.

Benbasat, I., \& Zmud, R. W. (1999). Empirical research in Information Systems: The practice of relevance. MIS Quarterly, 23(1), 3-16. Retrieved from http://doi.org/10.2307/249403

Birdsall, W. F. (2009). The role of the client in Informing Science: To be informed and to inform. Informing Science: The International Journal of an Emerging Transdiscipline, 12, 147-157.

Carlsson, S. A., Henningsson, S., Hrastinski, S., \& Keller, C. (2010). Socio-technical IS design science research: Developing design theory for IS integration management. Information Systems and EBusiness Management, 9(1), 109-131. Retrieved from http://doi.org/10.1007/s10257-010-0140-6

Chiasson, M., Reddy, M., Kaplan, B., \& Davidson, E. (2007). Expanding multi-disciplinary approaches to healthcare information technologies: What does Information Systems offer Medical Informatics? International Journal of Medical Informatics, 76, S89-S97. Retrieved from http://doi.org/10.1016/j.ijmedinf.2006.05.010 
Cohen, E. B. (1999). Reconceptualizing information systems as a field of the transdiscipline. Journal of Computing and Information Technology, 7(3), 213-219.

Cohen, E. B. (2009). A philosophy of Informing Science. Informing Science: The International Journal of an Emerging Transdiscipline, 12, 1-15.

Davenport, T. H., \& Markus, M. L. (1999). Rigor vs. relevance revisited: Response to Benbasat and Zmud. MIS Quarterly, 23(1), 19-23. Retrieved from http://doi.org/10.2307/249405

Drechsler, A. (2014). Extending the fitness-utility model for management artifacts in IS design science research. In M. C. Tremblay, D. VanderMeer, M. Rothenberger, A. Gupta, \& V. Yoon (Eds.), Advancing the impact of design science: Moving from theory to practice (pp. 337-344). Springer International Publishing. Retrieved from http://link.springer.com/chapter/10.1007/978-3-319-06701-8 24

Drechsler, A., \& Dörr, P. (2014). What kinds of artifacts are we designing? An analysis of artifact types and artifact relevance in IS journal publications. In M. C. Tremblay, D. VanderMeer, M. Rothenberger, A. Gupta, \& V. Yoon (Eds.), Advancing the impact of design science: Moving from theory to practice (pp. 329-336). Springer International Publishing. Retrieved from http://link.springer.com/chapter/10.1007/978-3-319-06701-8_23

Gill, G., \& Bhattacherjee, A. (2009). Whom are we informing? Issues and recommendations for MIS research from an informing sciences perspective. MIS Quarterly, 33, 217-235.

Gill, G., \& Hevner, A. R. (2013). A fitness-utility model for design science research. ACM Transactions on Management Information Systems, 4(2), 5:1-5:24. Retrieved from http://doi.org/10.1145/2499962.2499963

Gregor, S. (2006). The nature of theory in Information Systems. MIS Quarterly, 30(3), 611-642.

Gregor, S., \& Hevner, A. R. (2013). Positioning and presenting design science research for maximum impact. MIS Quarterly, 37(2), 337-356, A6.

Gregor, S., \& Jones, D. (2007). The anatomy of a design theory. Journal of the Association for Information Systems, 8(5), 312-335.

Hevner, A. R., \& Chatterjee, S. (2010). Design research in information systems: Theory and practice. New York: Springer.

Hevner, A. R., March, S. T., Park, J., \& Ram, S. (2004). Design science in Information Systems research. MIS Quarterly, 28(1), 75-105.

Hevner, A. R., Davis, C., Collins, R. W., \& Gill, T. G. (2014). A neurodesign model for IS research. Informing Science: the International Journal of an Emerging Transdiscipline, 17,103-132. Retrieved from http://www.inform.nu/Articles/Vol17/ISJv17p103-132Hevner.pdf

Iivari, J. (2003). The IS core - VII: Towards information systems as a science of meta-artifacts. Communications of the Association for Information Systems, 12(1). Retrieved from http://aisel.aisnet.org/cais/vol12/iss1/37

Kenneally, J., Curley, M., Wilson, B., \& Porter, M. (2013). Enhancing benefits from healthcare IT adoption using design science research: Presenting a unified application of the IT Capability Maturity Framework and the Electronic Medical Record Adoption Model. In M. Helfert \& B. Donnellan (Eds.), Design Science: Perspectives from Europe (pp. 124-143). Springer International Publishing. Retrieved from http://link.springer.com/chapter/10.1007/978-3-319-04090-5_12

Kock, N., Gray, P., Hoving, R., Klein, H., Myers, M. D., \& Rockart, J. (2002). IS research relevance revisited: Subtle accomplishment, unfulfilled promise, or serial hypocrisy? Communications of the Association for Information Systems, 8(1).

Krasnova, H., Spiekermann, S., Koroleva, K., \& Hildebrand, T. (2010). Online social networks: why we disclose. Journal of Information Technology, 25(2), 109-125. Retrieved from http://doi.org/10.1057/jit.2010.6 
Kuechler, W., \& Vaishnavi, V. (2008). The emergence of design research in Information Systems in North America. Journal of Design Research, 7(1), 1-16. Retrieved from http://doi.org/10.1504/JDR.2008.019897

Kuechler, W., \& Vaishnavi, V. (2011). Promoting relevance in IS research: An informing system for design science research. Informing Science: The International Journal of an Emerging Transdiscipline, 14(1), 125-138. Retrieved from http://www.inform.nu/Articles/Vol14/ISJv14p125-138Kuechler570.pdf

Kuechler, W., \& Vaishnavi, V. (2012). A framework for theory development in design science research: Multiple perspectives. Journal of the Association for Information Systems, 13(6), 395-423.

Maccani, G., Donnellan, B., \& Helfert, M. (2014). Action design research in practice: The case of smart cities. In M. C. Tremblay, D. VanderMeer, M. Rothenberger, A. Gupta, \& V. Yoon (Eds.), Advancing the impact of design science: Moving from theory to practice (pp. 132-147). Springer International Publishing. Retrieved from http://link.springer.com/chapter/10.1007/978-3-319-06701-8_9

March, S., \& Smith, G. (1995). Design and natural science research on information technology. Decision Support Systems, 15(4), 251-266. Retrieved from http://doi.org/10.1016/0167-9236(94)00041-2

Nicolai, A. T., \& Seidl, D. (2010). That's relevant! Different forms of practical relevance in Management Science. Organization Studies, 31(9/10), 1257-1285. Retrieved from http://doi.org/10.1177/0170840610374401

Nunamaker, Jr., J. F., \& Briggs, R. O. (2012). Toward a broader vision for Information Systems. ACM Transactions on Management Information Systems, 2(4), 20:1-20:12. Retrieved from http://doi.org/10.1145/2070710.2070711

Orlikowski, W. J., \& Iacono, C. S. (2001). Research commentary: Desperately seeking the "IT" in IT research-A call to theorizing the IT artifact. Information Systems Research, 12(2), 121-134. Retrieved from http://doi.org/10.1287/isre.12.2.121.9700

Pawson, R. (2006). Evidence-based policy: A realist perspective. London; Thousand Oaks, Calif.: SAGE.

Peffers, K., Tuunanen, T., Rothenberger, M., \& Chatterjee, S. (2007). A design science research methodology for Information Systems research. Journal of Management Information Systems, 24(3), 45-77. Retrieved from http://doi.org/10.2753/MIS0742-1222240302

Pernici, B., Aiello, M., vom Brocke, J., Donnellan, B., Gelenbe, E., \& Kretsis, M. (2012). What IS can do for environmental sustainability: A report from CAiSE'11 panel on Green and sustainable IS. Communications of the Association for Information Systems, 30(1), 18.

Reinecke, K., \& Bernstein, A. (2013). Knowing what a user likes: A design science approach to interfaces that automatically adapt to culture. MIS Quarterly, 37(2), 427-A11.

Rosseau, D. M. (2012). Envisioning evidence-based management. In D. M. Rosseau (Ed.), The Oxford handbook of evidence-based management (pp. 3-24). New York: Oxford University Press.

Sein, M., Henfridsson, O., Purao, S., Rossi, M., \& Lindgren, R. (2011). Action design research. MIS Quarterly, 35(1), 17-56.

Simon, H. A. (1996). The sciences of the artificial (3rd ed.). Cambridge, Massachusetts: MIT Press.

Vaishnavi, V., \& Kuechler, W. (2008). Design science research methods and patterns. Boca Raton, Florida: Auerbach.

Van Aken, J. E. (2004). Management research based on the paradigm of the design sciences: The quest for field-tested and grounded technological rules. Journal of Management Studies, 41(2), 219-246. Retrieved from http://doi.org/10.1111/j.1467-6486.2004.00430.x

VanderMeer, D., Dutta, K., \& Datta, A. (2012). A cost-based database request distribution technique for online e-commerce applications. Management Information Systems Quarterly, 36(2), 479-507.

Webster, J., \& Watson, R. T. (2002). Analyzing the past to prepare for the future: Writing a literature review. MIS Quarterly, 26(2), xiii-xxiii. 


\section{Biography}

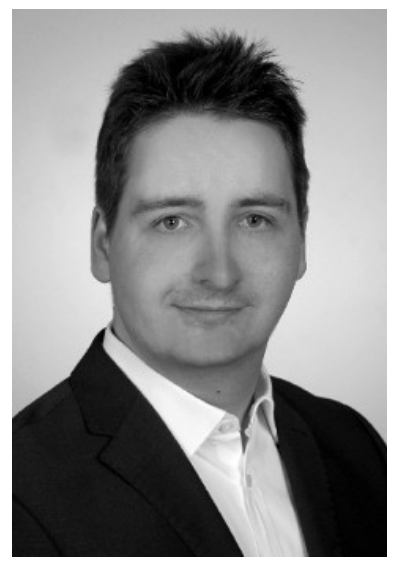

Andreas Drechsler is Visiting Scholar at the University of South Florida and post-doctoral researcher at the Institute of Computer Science and Business Information Systems at the University of Duisburg-Essen in Germany. He holds a doctoral degree from the latter institution. His research focuses, among other subjects, on improving design science research methods and methodologies in the Information Systems discipline. His industry experience consists of several years in software development and software project management. He has published in the Journal of Information Technology Theory, is author of over 20 research publications, and has given presentations at several international conferences. 